\title{
Erratum to: Validation of a clinical blood-based decision aid to guide immunotherapy treatment in patients with non-small cell lung cancer
}

Mirte Muller, Roland Hoogendoorn, Ruben J.G. Moritz, Vincent van der Noort, Mirthe Lanfermeijer, Catharina M. Korse, Daan van den Broek, Jelle J. ten Hoeve, Paul Baas, Huub H. van Rossum and Michel M. van den Heuvel

[Tumor Biology, 43, 2021, 115-127, DOI: 10.3233/TUB-211504]

The received and accepted dates provided in the original were incorrect. The correct dates are as follow:

Received 15 January 2021

Accepted 23 April 2021

The online file of the original article has been updated to reflect these changes. 